\title{
The Quality of Medicines in Community Pharmacies in Riyadh, Saudi Arabia: A Lot Quality Assurance Sampling (LQAS)-Based Survey
}

\author{
Hani M. J. Khojah ${ }^{1,2 *}$, Henrik Pallos ${ }^{3}$, Naoko Yoshida ${ }^{1}$, Manabu Akazawa ${ }^{4}$, Hirohito Tsuboi ${ }^{1}$, \\ Kazuko Kimura ${ }^{1}$ \\ ${ }^{1}$ Department of Drug Management and Policy, Graduate School of Natural Science and Technology, Kanazawa University, Kana- \\ zawa, Japan; ${ }^{2}$ Department of Clinical and Hospital Pharmacy, College of Pharmacy, Taibah University, Madinah, KSA; ${ }^{3}$ Department \\ of International Pharmaceutical Sciences, Graduate School of Natural Science and Technology, Kanazawa University, Kanazawa, \\ Japan; ${ }^{4}$ Department of Public Health and Epidemiology, Meiji Pharmaceutical University, Kiyose, Japan. \\ Email: "hani_khojah@yahoo.com
}

Received August $5^{\text {th }}, 2013$; revised September $5^{\text {th }}, 2013$; accepted September $21^{\text {st }}, 2013$

Copyright (C) 2013 Hani M. J. Khojah et al. This is an open access article distributed under the Creative Commons Attribution License, which permits unrestricted use, distribution, and reproduction in any medium, provided the original work is properly cited.

\begin{abstract}
Objectives: To classify community pharmacies (CPs) in Riyadh, Saudi Arabia, in terms of the quality of medicines sold by them, using the lot quality assurance sampling (LQAS) technique with a predefined threshold. Methods: Riyadh CPs were divided into 2 categories ("lots" for the purpose of LQAS), i.e., chain and independent CPs. Upper and lower rate thresholds for CPs that sell low-quality medicines were predefined as $20 \%$ and $5 \%$, respectively. Consumer and provider risks were predefined as 0.05 and 0.10 , respectively. The calculated number of randomly selected CPs required in each lot was 36; then, sale of low-quality medicines in $>3$ CPs implies a prevalence of $>20 \%$ of such CPs according to LQAS. A randomly selected brand of amoxicillin (selected as a quality indicator of medicines because it is both widely counterfeited and heat-sensitive) was purchased from each pharmacy by a "mystery shopper", checked for authenticity, and analyzed for drug content and content uniformity using a validated HPLC method. Results: Substandard amoxicillin was purchased in 9 pharmacies ( 4 chains and 5 independent). Both lots were thus rejected as unacceptable, which may indicate that consumers in Riyadh are at risk of purchasing substandard medicines at CPs. Conclusions: The quality of medicines sold in CPs in Riyadh did not meet our acceptability criterion, and appropriate intervention by decision makers is recommended. LQAS proved to be a practical, economical, and statistically valid sampling method for surveying the quality of medicines. It should enable decision makers to allocate resources for improvement more efficiently.
\end{abstract}

Keywords: Amoxicillin; Antibiotic; Quality of Medicines; Lot Quality Assurance Sampling; Saudi Arabia; Community Pharmacy

\section{Introduction}

Low-quality medicines are a global issue because of their increasing prevalence and the potentially serious consequences of their use [1,2]. Although developing countries are the principal targets of counterfeiters, developed countries also face many of the same risks [3,4]. Essential medicines (e.g., antimicrobials) are the most frequently targeted products in developing countries [5$8]$.

Low-quality medicines may be either counterfeit or substandard $[9,10]$. Regardless of the product quality and

${ }^{*}$ Corresponding author. amount of active ingredients, counterfeit medicines are defined as those made by unauthorized manufacturers with the intention of cheating, and this definition covers both the medicine and its packaging. Substandard medicines are produced by legitimate manufacturers, but do not fulfill the manufacturing quality standards or do not contain the correct amount of active ingredient(s). In addition, medicines that have passed their expiration date or that have deteriorated due to improper distribution and/or storage conditions (i.e., degraded medicines) may also be considered substandard, even if they were originally genuine and of good quality [11].

Studies with sound and replicable methodology on the 
quality of medicines in developing countries are very limited. Convenience sampling is widely used for this purpose, even though bias is clearly introduced because usually only accessible pharmacies or outlets are selected. Formal random sampling generally requires a larger sample, longer surveying time, and more resources. For these reasons, Lot Quality Assurance Sampling (LQAS) has been proposed as an economical technique to survey the quality of medicines sold in community pharmacies (CPs) [11]. LQAS was developed in the 1920s to assess the quality of industrial products by inspecting random samples [12]. It was later adapted for a variety of health surveys and settings, though not surveys of the quality of medicines in the supply chain $[13,14]$. Because LQAS uses a relatively small sample, it cannot determine the prevalence (rate) of outlets that sell low-quality medicines, but rather provides a way to classify the rate as either acceptable or unacceptable in terms of predetermined criteria. Thus, it may be helpful to enable decision makers to properly allocate and distribute resources among various supervisory areas, and also provides an indication as to whether or not larger-scale, randomized surveys are required.

In Saudi Arabia self-medication is common and various prescription medicines, including antibiotics, can be purchased from CPs without a prescription, despite the government's regulations $[15,16]$. Recently, the Saudi Food and Drug Authority (SFDA) was es- tablished as an independent corporate body that reports directly to the President of the Council of Ministers. It is responsible for ensuring the safety of food and drugs for human and veterinary use and the safety of biological and chemical substances and medical devices [17].

Among antibiotics, amoxicillin is widely used in developing countries, and it is included in the list of essential drugs issued by the World Health Organization (WHO) [18]. It is also considered an essential drug in primary health care in Saudi Arabia [19]. It is also among the most widely counterfeited medicines in developing countries [3,5]. Substandard amoxicillin has already been identified in Saudi Arabia in one study [8]. Furthermore, amoxicillin products, including suspensions and capsules, are sensitive to heat and may degrade easily at temperatures above $30^{\circ} \mathrm{C}$ [20]. Therefore, we focused on amoxicillin as an indicator of the quality of medicines in the supply chain in Saudi Arabia, where high temperatures are common.

We aimed to explore the quality of amoxicillin capsules and tablets sold in CPs in Riyadh, Saudi Arabia, as an indicator of the quality of medicines sold in these pharmacies, using the LQAS technique. Based on a review of the literature on the quality of amoxicillin in developing countries $[3,5,8,21,22]$, we formulated as our null hypothesis that more than $20 \%$ of the CPs in Riyadh, in either the chain or independent category, sell lowquality amoxicillin.

\section{Methods}

This study was approved by the Ethical Committee of Kanazawa University and by the SFDA. Samples in the original packaging were collected between September 21 and October 3, 2010, individually placed in sealed bags, packed in thermally insulated plastic cool boxes, and shipped to Kanazawa University, Japan, via a secure courier after obtaining the necessary clearance documents. The analysis was performed in the Department of Drug Management and Policy at Kanazawa University between May 25, 2011 and February 7, 2012 (before the expiration dates of all samples). The cool boxes were kept in the laboratory at a controlled room temperature of $22^{\circ} \mathrm{C}$ until analysis.

Because 2 levels of sampling (pharmacies and amoxicillin brands) were included in this study, the term "sample" is used to indicate amoxicillin samples and the term "subject" for the pharmacies selected for the study. The term "target pharmacy" refers to a pharmacy that sold low-quality amoxicillin. In general, the survey methodology and reporting were consistent with the Medicine Quality Assessment Reporting Guidelines (MEDQUARG) proposed by Newton et al. [11].

\subsection{Selection of Pharmacies}

A list of registered CPs in Riyadh was obtained from the Saudi Ministry of Health (MOH) in July 2010 (1367 pharmacies). The pharmacies were divided into 2 categories, i.e., chain and independent (869 and 498 pharmacies, respectively). An independent pharmacy was defined as one belonging to a group of $\leq 3$ pharmacies, whereas a chain pharmacy was defined as one belonging to a group of $>3$ pharmacies [23]. Each category was designated as a "lot"for the purpose of LQAS.

The required number of pharmacies in each lot and the decision rule were calculated according to the LQAS technique. The binomial LQAS formula (Figure 1(a)) is preferred if the population size is either unknown or very large [24]. In the present study, we used the hypergeometric LQAS model (Figure 1(b)) because each subject pharmacy was included only once and because the population size of pharmacies in each lot was known and relatively small $[25,26]$. These characteristics allow the actual errors to be calculated more accurately. In this model, the gamma function was used for the calculation of factorials of fractions (Figure 1(c)). A calculator that uses this calculation method is available online [27].

Studies from developing countries have reported a 
variety of rates of sale of counterfeit and substandard antimicrobials ranging from $2.8 \%$ to $>50 \%$, with the majority of the rates lying within the range of $30 \%-40 \%$ [3]. In addition, various levels of amoxicillin content, ranging from $0 \%$ to $85 \%$ of the labeled amount, have been reported $[3,5,8,21,22]$. Based on the above reports, we adopted the following upper and lower prevalence thresholds in this study: a lot with a rate of target pharmacies $>20 \%$ was classified as a high-prevalence lot (so that the null hypothesis was not rejected for this lot), whereas a lot with a rate of target pharmacies $\leq 5 \%$ was classified as a low-prevalence lot. This criterion for the low-prevalence lot is considered acceptable, because it is preferable to devote limited resources to improve CPs in the high-prevalence lot. The consumer risk (alpha error based on the null hypothesis) and the provider risk (beta error) were predetermined to be $\leq 0.05$ and $\leq 0.10$, respectively.

The minimum number of subject pharmacies that produced the lowest combination of cumulative errors at both thresholds was 36 pharmacies in each lot, with 3 as the value for the decision rule (Table 1). If the number of target pharmacies in either lot exceeds the decision value, the lot is classified as a high-prevalence lot and the null hypothesis is not rejected. Otherwise, the lot will be classified as a low-prevalence lot. The LQAS decision rule only classifies the rate as either $>$ the predefined upper threshold or $\leq$ the predefined lower threshold. It is not sensitive to rates between these thresholds. It is worth mentioning that formal random sampling would have (a)

$P_{x}=\frac{n !}{x !(n-x) !} p^{x} q^{n-x} \quad P_{x}$
$\mathrm{P}=$ the probability calculated at $\mathrm{p}$.
$\mathrm{x}=$ decision rule $=$ number of target
pharmacies out of $\mathrm{n}$.
$\mathrm{n}=$ required number of subject pharmacies.
$\mathrm{p}=$ predefined prevalence (rate) threshold of
target pharmacies.
$\mathrm{q}=$ predefined prevalence (rate) threshold of
non-target pharmacies (i.e., $1-\mathrm{p}$ ).

(b)

$P_{x}=\frac{\left(\begin{array}{l}S \\ x\end{array}\right)\left(\begin{array}{l}N-S \\ n-x\end{array}\right)}{\left(\begin{array}{l}N \\ n\end{array}\right)}$

$$
\begin{aligned}
& \mathrm{S}=\text { predefined number of target } \\
& \text { pharmacies out of } \mathrm{N}(\text { i.e., } \mathrm{p} \cdot \mathrm{N}) . \\
& \mathrm{N}=\text { population size of a lot. } \\
& \left(\begin{array}{l}
a \\
b
\end{array}\right)=\frac{a !}{b !(a-b) !}
\end{aligned}
$$

$\Gamma$ (a) is the gamma function of a.
Figure 1. The LQAS Equations. (a) The binomial formula;

\begin{tabular}{|c|c|c|c|c|c|}
\hline $\mathrm{x}$ & $\begin{array}{c}\text { Sensitivity } \\
\text { (at upper threshold of } 0.20 \text { ) }\end{array}$ & $\begin{array}{l}\text { Cumulative alpha error } \\
\text { (consumer risk) }\end{array}$ & $\begin{array}{l}\text { Cumulative specificity } \\
\text { (at lower threshold of } 0.05 \text { ) }\end{array}$ & $\begin{array}{c}\text { Beta error } \\
\text { (provider risk) }\end{array}$ & Total error \\
\hline \multicolumn{6}{|c|}{ For chain pharmacies $(N=869)$ when $n=36$} \\
\hline 0 & 0.9997 & 0.0003 & 0.1517 & 0.8483 & 0.8486 \\
\hline 1 & 0.9972 & 0.0028 & 0.4519 & 0.5481 & 0.5509 \\
\hline 2 & 0.9855 & 0.0145 & 0.7336 & 0.2664 & 0.2809 \\
\hline 3 & 0.9512 & 0.0488 & 0.9006 & 0.0994 & 0.1482 \\
\hline 4 & 0.8783 & 0.1217 & 0.9708 & 0.0292 & 0.1509 \\
\hline 5 & 0.7591 & 0.2409 & 0.9931 & 0.0069 & 0.2478 \\
\hline 6 & 0.6027 & 0.3973 & 0.9987 & 0.0013 & 0.3986 \\
\hline \multicolumn{6}{|c|}{ For independent pharmacies $(N=498)$ when $n=36$} \\
\hline 0 & 0.9998 & 0.0002 & 0.1471 & 0.8529 & 0.8531 \\
\hline 1 & 0.9975 & 0.0025 & 0.4481 & 0.5519 & 0.5544 \\
\hline 2 & 0.9866 & 0.0134 & 0.7348 & 0.2652 & 0.2786 \\
\hline 3 & 0.9538 & 0.0462 & 0.9039 & 0.0961 & 0.1423 \\
\hline 4 & 0.8823 & 0.1177 & 0.9732 & 0.0268 & 0.1445 \\
\hline 5 & 0.7633 & 0.2367 & 0.9941 & 0.0059 & 0.2426 \\
\hline 6 & 0.6054 & 0.3946 & 0.999 & 0.001 & 0.3956 \\
\hline
\end{tabular}
(b) the hypergeometric formula; (c) the factorial of a fraction.

Table 1. Part of the calculation process for deciding the required number of subject pharmacies and the decision rule.

The first 7 rows of probability combinations are shown. $\mathrm{x}=$ decision rule, $\mathrm{N}=$ population size, $\mathrm{n}=$ required number of subject pharmacies, sensitivity $=1-$ cumulative alpha error, Beta error $=1-$ cumulative specificity. Minimum accepted errors (and their sum) occur when $\mathrm{x}=3$ in the round of $\mathrm{n}$ when $\mathrm{n}=36$ for each lot (shaded areas of the table). This indicates that the smallest required number of subject pharmacies is 36 . If the calculation continues, other good combinations will be obtained. However, this would require additional pharmacies. At $n=36$, the finding of $\leq 3$ target pharmacies indicates that their rate in the corresponding lot is $\leq 5 \%$. However, this rate is acceptable according to the predefined thresholds in this study. The finding of $>3$ target pharmacies means that their rate is $>20 \%$. Because this rate is unacceptable, the corresponding lot (i.e., category of pharmacy) is rejected. 
required a 4- to 5-fold larger number of pharmacies in each category, and therefore the resources required would have been 4- to 5-fold greater. This represents a significant advantage for LQAS.

A list of pharmacies in each category was created and each pharmacy was coded. The lists were scrambled, and 45 pharmacies $(36+9)$ were randomly selected from each list with MS Excel 2010 (Microsoft Co., USA). The additional 9 pharmacies represented a reserve for an estimated dropout rate of $25 \%$. Dropout could be for any of the following reasons: a) the pharmacy was closed on the second visit; b) the pharmacy was out of business; c) the pharmacy did not have the required quantity of amoxicillin dosage units; or d) the pharmacy refused to sell amoxicillin without a prescription.

In theory, LQAS sampling can be terminated if the decision rule is exceeded at an early stage of the survey, thereby minimizing cost and time requirements, though this was not the case in the present study.

\subsection{Amoxicillin Sampling}

The "mystery shopper" technique with the same scenario was used in purchasing samples [28,29]. The sampler asked the seller to show him all brands of amoxicillin capsules and tablets available in 4 - 5 packs ( 80 dosage units) because one of the sampler's friends wanted the medicine. The sampler also told the seller that he would call his friend to tell him about the available brands and strengths to allow the friend to select the product to be purchased. The brands were numbered in a list reflecting the order in which the seller presented them, excluding any clavulanate-containing products. Each strength of a given brand was treated as a separate brand. A mobile telephone was used to rapidly generate a random number between 1 and the highest number on the list with Excel Mobile. This procedure was conducted while the sampler appeared to be making the call. In this way, one brand was randomly purchased from each randomly selected pharmacy. If the packs were from more than one batch of the same brand, they were considered as different samples purchased from the same pharmacy. Packs from the same batch of the same brand purchased from different pharmacies were also considered as different samples.

After sampling, the sampling form was immediately completed outside the pharmacy (Table 2). Samples were immediately placed in a plastic cool box and the car air-conditioner was operating effectively during all sampling trips. Amoxicillin brands were coded with the letters A-P.

\subsection{Authenticity Investigations}

Dosage units, strips, boxes, and package inserts of all samples were visually inspected. Parts of all those items
Table 2. Sampling information.

\begin{tabular}{cc}
\hline Pharmacy code and type & Dosage form \\
Sample code & Strength \\
Sampling date & Package size \\
Package condition and type & $\begin{array}{c}\text { Registration number in } \\
\text { Saudi Arabia }\end{array}$ \\
Trade name & Batch number \\
Manufacturer's name & Manufacture date \\
Manufacturer's country & Expiration date \\
Distributor in Saudi Arabia & Price \\
\hline
\end{tabular}

were sent to the corresponding manufacturers for authenticity confirmation. The SFDA was contacted to verify the registration status of the products.

\subsection{Analysis and Materials}

The samples were analyzed in the order of their expiration dates. The content uniformity test was performed according to the 34th edition of the United States Pharmacopeia (USP), but using a shorter HPLC column $(15 \mathrm{~cm}$ instead of $25 \mathrm{~cm})[30,31]$. The use of the shorter column would not have affected the results, since the method was validated. For every sample the amoxicillin content, which should range from $90.0 \%-120.0 \%$ for capsules and $90.0 \%-110.0 \%$ for tablets, according to the USP, was calculated by averaging the content of the dosage units analyzed in the content uniformity test.

All chemicals used were of analytical grade. Acetonitrile, potassium dihydrogen phosphate, and potassium hydroxide were purchased from Nakalai Tesque (Kyoto, Japan). Standard amoxicillin, conforming to the USP Reference Standard (USPRS), was obtained from the Department of Medical Sciences, Bureau of Drugs and Narcotics, Ministry of Public Health, Thailand. Standard cefadroxil, from Sigma (St Louis, MO, USA), was used as the internal standard.

The HPLC system consisted of the following components from JASCO (Tokyo, Japan): a pump (PU-2080 Plus), a UV detector (UV-2075 Plus) set at $230 \mathrm{~nm}$, a column thermostat (CO-1560), a degasser (DG-980-50), a system controller (LC-Net II/ADC), and an autosampler (AS-950). The system was equipped with a $4.6 \times$ $150 \mathrm{~mm}$ Shim-pack CLC-ODS (M) column from Shimadzu (Kyoto, Japan), filled with $70 \%$ methanol. The system was linked with a computer running ChromNav software from JASCO (Tokyo, Japan) to analyze the results and to plot curves and peaks.

A calibration curve was produced daily, using 3 concentrations of standard amoxicillin $(0.05,0.10$, and 
$0.2 \mathrm{mg} / \mathrm{mL}$ ) prepared from a fresh stock solution of 1 $\mathrm{mg} / \mathrm{mL}$ amoxicillin (on anhydrous base). The linearity of the standard amoxicillin/diluent solution was maintained between 0.025 and $0.5 \mathrm{mg} / \mathrm{mL}$ and the analytical range was $0.05-0.4 \mathrm{mg} / \mathrm{mL}$. A stock solution of standard cefadroxil $(0.2 \mathrm{mg} / \mathrm{mL}$, on anhydrous base) was also freshly prepared daily and was added to all sample and calibration solutions to obtain a final concentration of 0.1 $\mathrm{mg} / \mathrm{mL}$ in each solution.

The final sample and calibration solutions were filtered through $0.2 \mu \mathrm{m}$ Minisart RC 4 syringe filters from Sartorius Stedim (Dublin, Ireland). All solutions were used within 6 hours of preparation and analyzed in triplicate.

For method validation, intra- and inter-day precision tests were performed using standard amoxicillin, and the accuracy was evaluated by applying the standardaddition (spiking) recovery technique, using aliquots of pre-analyzed samples. All values of standard deviation, relative standard deviation, and relative error for both precision and accuracy were $<2 \%$, based on a $95 \%$ confidence interval. These values were considered satisfactory.

\section{Results}

Eighty-three samples were collected from the 72 pharmacies. Of these samples, 41 were collected from chain pharmacies and 42 from independent pharmacies (Table 3). Six samples $(7 \%)$ were tablets and the others were capsules. Twenty-eight samples $(35 \%)$ were locally manufactured, 47 (57\%) were imported from other Arab countries, and 7 (8\%) were imported from Europe. The samples included 16 brands produced by 10 manufacturers. These samples represented all the manufacturers registered by the SFDA at the time of sampling. The dropout rate was 7 and 6 for chain and independent pharmacies, respectively. Dropouts occurred for the reasons mentioned above, and no major differences in reasons for dropping out were found between the independent and chain categories.

The authenticity of the samples was confirmed by all manufacturers, and the registration status of each product and manufacturer was confirmed by the SFDA.

A total of 9 samples (11\%), all of which were capsules, failed the content uniformity test. The failed samples were purchased from 9 pharmacies (4 chain and 5 independent) that belonged to different chains or owners and included 5 brands from 4 manufacturers (Figure 2). The content of 6 of the failed samples was below $90 \%$. The lowest content was $80.7 \%$ and the content of the approved samples ranged from $90.6 \%$ to $104.2 \%$ (Figure 3). Interestingly, certain batches of certain brands passed the content and/or content uniformity tests in some

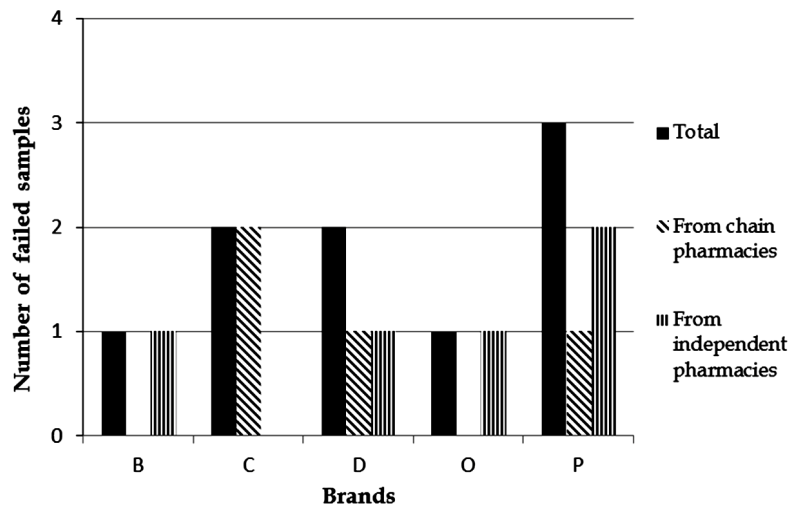

Figure 2. Distribution of failed samples.

Table 3. Distribution of samples and batches.

\begin{tabular}{|c|c|c|c|c|}
\hline \multirow[b]{2}{*}{$\begin{array}{l}\text { Brand } \\
\text { code }\end{array}$} & \multicolumn{3}{|c|}{ Number of samples ${ }^{a}$} & \multirow[b]{2}{*}{$\begin{array}{c}\text { Number of } \\
\text { batches }\end{array}$} \\
\hline & $\begin{array}{c}\text { From } 36 \text { chain } \\
\text { pharmacies }\end{array}$ & $\begin{array}{c}\text { From } 36 \\
\text { independent } \\
\text { pharmacies }\end{array}$ & Total & \\
\hline$A^{c}$ & 4 & 4 & 8 & 3 \\
\hline $\mathrm{B}^{\mathrm{c}}$ & 4 & 3 & 7 & 5 \\
\hline$C^{d}$ & 2 & 0 & 2 & 2 \\
\hline$D^{d}$ & 3 & 4 & 7 & 6 \\
\hline$E^{d}$ & 3 & 7 & 10 & 6 \\
\hline $\mathrm{F}^{\mathrm{e}}$ & 1 & 0 & 1 & 1 \\
\hline $\mathrm{G}^{\mathrm{e}}$ & 2 & 0 & 2 & 2 \\
\hline $\mathrm{H}^{\mathrm{d}}$ & 0 & 1 & 1 & 1 \\
\hline$I^{d}$ & 6 & 1 & 7 & 5 \\
\hline $\mathrm{J}^{\mathrm{c}}$ & 1 & 5 & 6 & 4 \\
\hline $\mathrm{K}^{\mathrm{d}}$ & 3 & 2 & 5 & 3 \\
\hline$L^{e}$ & 0 & 4 & 4 & 3 \\
\hline$M^{\mathrm{d}}$ & 4 & 6 & 10 & 10 \\
\hline $\mathrm{N}^{\mathrm{c}}$ & 2 & 0 & 2 & 2 \\
\hline $\mathrm{O}^{\mathrm{c}}$ & 5 & 1 & 6 & 2 \\
\hline $\mathrm{P}^{\mathrm{d}}$ & 1 & 4 & 5 & 3 \\
\hline Total & 41 & 42 & 83 & 57 \\
\hline
\end{tabular}

${ }^{\mathrm{a}} \mathrm{A}$ sample is a batch purchased from a single pharmacy. If the same batch is purchased at another pharmacy, it is considered as a different sample. Different batches of the same brand purchased from the same pharmacy are also considered as different samples. ${ }^{b}$ The number of batches of the corresponding brand purchased from all pharmacies without repetition. ${ }^{\mathrm{c}}$ Manufactured in Saudi Arabia. ${ }^{\mathrm{d} I m p o r t e d ~ f r o m ~ o t h e r ~ A r a b ~ c o u n t r i e s . ~}{ }^{\mathrm{C}}$ Imported from $\mathrm{Eu}-$ rope.

pharmacies, but failed in others (Table 4).

The number of target pharmacies in each lot was greater than the decision value. For this reason, we failed 


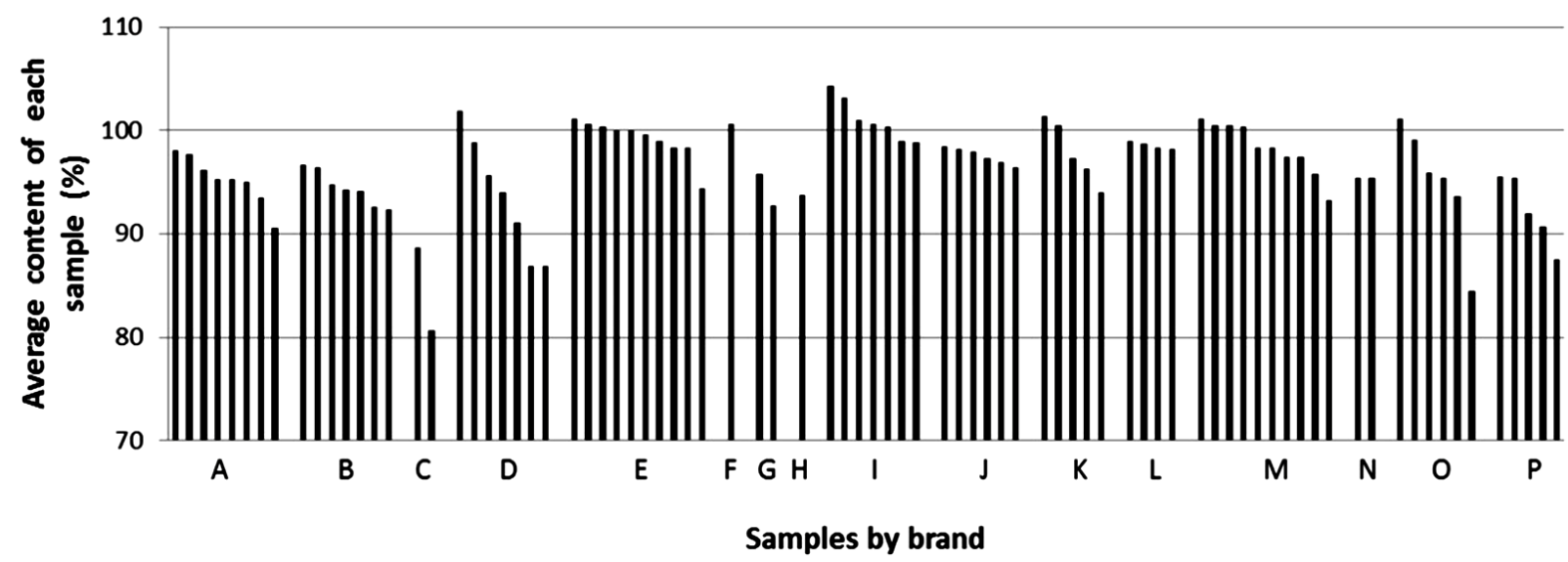

Figure 3. Content distribution of all samples.

Table 4. Batches that passed in some pharmacies but failed in others.

\begin{tabular}{|c|c|c|c|c|c|}
\hline \multirow{2}{*}{ Brand } & \multicolumn{2}{|c|}{ Samples of the same batch } & \multirow{2}{*}{$\begin{array}{c}\text { Content uniformity } \\
\text { acceptance value (\%) }\end{array}$} & \multirow{2}{*}{ Average content $(\%)$} & \multirow{2}{*}{ Pharmacy type } \\
\hline & No. & Status & & & \\
\hline \multirow{2}{*}{ B } & 1 & Failed & 15.66 & 92.36 & Independent \\
\hline & 2 & Passed & 07.35 & 94.74 & Independent \\
\hline \multirow{2}{*}{$\mathrm{D}$} & 1 & Failed & 19.92 & 86.81 & Independent \\
\hline & 2 & Passed & 14.20 & 91.11 & Independent \\
\hline \multirow{4}{*}{$\mathrm{O}$} & 1 & Failed & 27.06 & 84.43 & Independent \\
\hline & 2 & Passed & 05.57 & 95.96 & Chain \\
\hline & 3 & Passed & 08.46 & 95.38 & Chain \\
\hline & 4 & Passed & 13.21 & 93.57 & Chain \\
\hline \multirow{3}{*}{$\mathrm{P}$} & 1 & Failed & 15.08 & 90.66 & Independent \\
\hline & 2 & Failed & 17.24 & 91.89 & Independent \\
\hline & 3 & Passed & 08.26 & 95.41 & Independent \\
\hline
\end{tabular}

${ }^{\mathrm{a}}$ Acceptance value must be $\leq 15 \%$.

to reject the null hypothesis, and both lots were classified as high-prevalence lots. Thus, our results indicate that more than $20 \%$ of the pharmacies in each lot sell lowquality amoxicillin, an outcome suggestive of a significant problem with important public health implications.

\section{Discussion}

Substandard samples amounted to $11 \%$ of the total samples, indicating a rather high prevalence of substandard amoxicillin products in CPs in Riyadh. This is consistent with the findings of Kyriacos et al., although the sample size for amoxicillin products purchased in Saudi Arabia was not specified in that study [8]. Like them, we found that all European samples passed the quality tests, although the percentage of European samples in the present work was very low (8\%). All tablet forms passed the quality tests in our study, but again the significance of this result is uncertain because of the small percentage of tablets (7\%). According to the SFDA (e-mail communication, Jul 6, 2010), the sales of tablet forms and European brands in Saudi Arabia during the second quarter of 2009 amounted to $3.96 \%$ and $4.32 \%$ of the total sales of amoxicillin (capsules and tablets), respectively.

The finding that some samples from the same batch passed the tests in certain pharmacies, but failed in others, suggests the occurrence of degradation of the failed samples, which may originally have been of good quality. Degradation may have occurred due to poor storage and/ or distribution conditions. The samples were collected during a very hot season, when the outside temperature 
in Riyadh during daytime reached approximately $45^{\circ} \mathrm{C}$. Poor temperature control in the distributors' facilities, such as warehouses and delivery vehicles, could have been resulted in degradation of amoxicillin. Although the air conditioning in the vast majority of the visited pharmacies was satisfactory during sampling, the possibility that the air conditioners had failed or were not in use in certain pharmacies at certain times cannot be excluded. However, we cannot exclude poor quality-control practices during the manufacturing process. This possibility is supported by the fact that powder in some capsules of failed samples from one manufacturer was in the form of a hard mass, possibly formed when the samples dried out after having absorbed moisture. Thus, poor packaging may have been a contributory factor.

The average content of the active ingredient in failed samples was greater than $80 \%$. This value contrasts with the low value found by Kyriacos et al. (59\%) [8]. However, our results seem consistent with the findings of a study conducted in Indonesia, where $20 \%$ of the amoxicillin tablets analyzed contained an amount of active ingredient that was only slightly below the acceptable range according to the British Pharmacopeia (BP) [22]. Note that in our study two more samples would have failed the content test (1 sample from each lot), based on the content range of $92.5 \%-110.0 \%$ specified in BP 2012 [32]. The intake of poor-quality antibiotics may lead to therapeutic failure and the emergence of bacterial resistance [3].

The number of target pharmacies exceeded the decision value in both lots (i.e., chain and independent categories). This finding suggests that intervention strategies should target both types of CPs. Further, the unacceptable rate of CPs that sell low-quality medicines in Riyadh, a capital city where inspection and monitoring are expected to be relatively strict, suggests that the situation may be even worse in other cities or more remote areas of the country. It might be advisable for the SFDA to perform routine monitoring of wholesalers and pharmacy storage facilities, distribution facilities, and environmental conditions inside pharmacies (e.g., temperature, humidity, and exposure to sunlight). In addition, distributors, pharmacy owners, and pharmacists should be educated about the possible consequences of failing to adhere to appropriate distribution and storage conditions for the provision of medicines.

LQAS proved to be a practical method for surveying the quality of medicines sold in CPs, using rather small numbers of pharmacies for sampling, and it may be a suitable approach for future monitoring by the SFDA or other investigators in Saudi Arabia, as well as other countries. The same methodology can be used for followup to monitor changes that may have occurred following interventions. However, the medicine selected as an indicator of the quality of medicines may need to be changed according to the nature of the study or the geographical area surveyed. In our study, amoxicillin was selected because it is widely used, widely counterfeited, and heat-labile (Riyadh is very hot during summer), and also because substandard amoxicillin was reported in Saudi Arabia in one study.

\section{Limitations}

The following limitations may have influenced the results of this study. First, only capsule and tablet dosage forms of amoxicillin were sampled. Therefore, the findings cannot necessarily be extended to other dosage forms or other medicines.

Second, it was not possible to collect samples of a single batch from each pharmacy because asking the seller about batches would have revealed that the pharmacy was under investigation.

Third, samples were analyzed by the chief investigator, who was not blinded as to the samples being analyzed, but was blinded as to the pharmacy from which the sample(s) were obtained. Unintentional expectation bias might have been introduced because the chief investigator is a Saudi clinical pharmacist. However, this factor is unlikely to have affected the results of the study, because there were several samples that failed from certain pharmacies but passed from others, and because the samples were repeatedly measured with a validated method.

Fourth, only content and content uniformity tests were conducted. Therefore, "quality" in this study refers only to the acceptable amount and uniformity of the active ingredient in terms of the ranges specified by the USP.

Finally, because some samples passed the content test while other samples from the same batch but purchased from different pharmacies failed it, we assumed that the failed samples had been degraded. However, we did not analyze them for degradation products. There are several methods that can differentiate between degraded and originally substandard amoxicillin [33,34]. These methods may be used in future studies.

\section{Conclusions}

Although this study has several limitations, the results indicate that there are deficiencies in quality control within the supply chain (including customs clearance of imported medicines) and/or in storage facilities in Riyadh, either at the level of wholesalers or pharmacies, in addition to possible manufacturing or packaging defects in some brands of amoxicillin.

LQAS with a mystery shopper provided a readily reproducible and statistically valid sampling method for 
investigating the quality of medicines sold at CPs.

Finally, we recommend further studies to investigate the adherence of CPs, and other facilities in the supply chain in Riyadh, to optimal conditions for keeping and selling medicines. Larger-scale randomized surveys would be helpful to further delineate the scale of the quality-control problem in CPs.

\section{Acknowledgements}

The authors would like to thank the Heiwa Nakajima Foundation (a Japanese nonprofit organization) and the Prioritized Research Programs at Kanazawa University for funding. Thanks are also offered to the SFDA for approving the study and inviting the research team to Saudi Arabia. The authors especially thank Prof. Saleh A. Bawazir, Dr. Hajed M. Hashan, Mr. Bassam Alwon, Mr. Sami Al Sager, and Mr. Adnan Jannadi from the SFDA and Mr. Abdulrahman Al Sahbi from the Saudi $\mathrm{MOH}$ for all the assistance that they provided in obtaining information about pharmacies and medicines. The authors finally thank the following manufacturers, who responded to the authenticity check and agreed to allow us to mention their names: Saudi Pharmaceutical Industries and Medical Appliances Corporation (Saudi Arabia), Jazeera Pharmaceutical Industries (Saudi Arabia), The Arab Pharmaceutical Manufacturing Co. Ltd (Jordan), Dar Al Dawa Development \& Investment Co. Ltd. (Jordan), and Astellas Pharma Inc. (Japan office).

\section{Authors' Contributions}

Research protocol development: HMJK, HP, MA, and KK. Sampling: HMJK, HP, and KK. Sample analysis protocol development: HMJK, NY, and KK. Sample analysis: HMJK. Manuscript draft: HMJK. Manuscript revision: HMJK, HP, NY, HT, and KK. Obtaining research funds: HT and KK.

Parts of this study were presented in a poster (Poster No. 460) at the FIP Centennial Congress of Pharmacy and Pharmaceutical Sciences, 2012, held in Amsterdam.

\section{REFERENCES}

[1] M. ten Ham, "Health Risks of Counterfeit Pharmaceuticals," Drug Safety, Vol. 26, No. 14, 2003, pp. 991-997. http://dx.doi.org/10.2165/00002018-200326140-00001

[2] S. E. Nsimba, "Problems Associated with Substandard and Counterfeit Drugs in Developing Countries: A Review Article on Global Implications of Counterfeit Drugs in the Era of Antiretroviral (ARVs) Drugs in a Free Market Economy," East African Journal of Public Health, Vol. 5, No. 3, 2008, pp. 205-210.

[3] T. Kelesidis, I. Kelesidis, P. I. Rafailidis and M. E. Falagas, "Counterfeit or Substandard Antimicrobial Drugs: A
Review of the Scientific Evidence," Journal of Antimicrobial Chemotherapy, Vol. 60, No. 2, 2007, pp. 214-236. http://dx.doi.org/10.1093/jac/dkm109

[4] R. Watson, "European Union Prepares to Tackle Counterfeit Drugs," British Medical Journal, Vol. 340, 2010, p. c2425. http://dx.doi.org/10.1136/bmj.c2425

[5] E. Wondemagegnehu, "Counterfeit and Substandard Drugs in Myanmar and Viet Nam - Report of a Study Carried out in Cooperation with the Governments of Myanmar and Viet Nam," 2011.

http://apps.who.int/medicinedocs/pdf/s2276e/s2276e.pdf

[6] M. H. Khan, J. Okumura, T. Sovannarith, N. Nivanna, M. Akazawa and K. Kimura, "Prevalence of Counterfeit Anthelminthic Medicines: A Cross-Sectional Survey in Cambodia," Tropical Medicine and International Health, Vol. 15, No. 5, 2010, pp. 639-644.

http://dx.doi.org/10.1111/j.1365-3156.2010.02494.x

[7] P. N. Newton, M. D. Green, D. C. Mildenhall, A. Plançon, H. Nettey, L. Nyadong, D. M. Hostetler, I. Swamidoss, G. A. Harris, K. Powell, A. E. Timmermans, A. A. Amin, S. K. Opuni, S. Barbereau, C. Faurant, R. C. W. Soong, K. Faure, J. Thevanayagam, P. Fernandes, H. Kaur, B. Angus, K. Stepniewska, P. J. Guerin and F. M. Fernández, "Poor Quality Vital Anti-Malarials in Africa-An Urgent Neglected Public Health Priority," Malaria Journal, Vol. 10, 2011, p. 352.

http://dx.doi.org/10.1186/1475-2875-10-352

[8] S. Kyriacos, M. Mroueh, R. P. Chahine and O. Khouzam, "Quality of Amoxicillin Formulations in Some Arab Countries," Journal of Clinical Pharmacy and Therapeutics, Vol. 33, No. 4, 2008, pp. 375-379.

http://dx.doi.org/10.1111/j.1365-2710.2008.00926.x

[9] World Health Organization, "Counterfeit Drugs. Guidelines for the Development of Measures to Combat Counterfeit Drugs," 2011.

http://whqlibdoc.who.int/hq/1999/WHO_EDM_QSM_99. 1.pdf

[10] World Health Organization, "Counterfeit Medicines: Some Frequently Asked Questions," 2011.

http://www.wpro.who.int/mediacentre/factsheets/fs_2005 0506/en/index.html

[11] P. N. Newton, S. J. Lee, C. Goodman, F. M. Fernández, S. Yeung, S. Phanouvong, H. Kaur, A. A. Amin, C. J. M. Whitty, G. O. Kokwaro, N. Lindegårdh, P. Lukulay, L. J. White, N. P. J. Day, M. D. Green and N. J. White, "Guidelines for Field Surveys of the Quality of Medicines: A Proposal," PLoS Medicine, Vol. 6, No. 3, 2009, Article ID: e1000052. http://dx.doi.org/10.1371/journal.pmed.1000052

[12] W. A. Reinke, "Applicability of Industrial Sampling Techniques to Epidemiologic Investigations: Examination of an Underutilized Resource," American Journal of Epidemiology, Vol. 134, No. 10, 1991, pp. 1222-1232.

[13] S. E. Robertson and J. J. Valadez, "Global Review of Health Care Surveys Using Lot Quality Assurance Sampling (LQAS), 1984-2004," Social Science \& Medicine, Vol. 63, No. 6, 2006, pp. 1648-1660.

http://dx.doi.org/10.1016/j.socscimed.2006.04.011 
[14] A. Bhuiya, S. M. A. Hanifi, N. Roy and P. K. Streatfield, "Performance of the Lot Quality Assurance Sampling Method Compared to Surveillance for Identifying Inadequately-Performing Areas in Matlab, Bangladesh," Journal of Health, Population, and Nutrition, Vol. 25, No. 1, 2007, pp. 37-46.

[15] S. A. Bawazir, "Prescribing Pattern at Community Pharmacies in Saudi Arabia," International Pharmacy Journal, Vol. 6, No. 5, 1992, pp. 222-224.

[16] A. A. Bin Abdulhak, M. A. Altannir, M. A. Almansor, M. S. Almohaya, A. S. Onazi, M. A. Marei, O. F. Aldossary, S. A. Obeidat, M. A. Obeidat, M. S. Riaz and I. M. Tleyjeh, "Non Prescribed Sale of Antibiotics in Riyadh, Saudi Arabia: A Cross Sectional Study," BMC Public Health, Vol. 11, No. 1, 2011, p. 538.

http://www.biomedcentral.com/1471-2458/11/538

http://dx.doi.org/10.1186/1471-2458-11-538

[17] Saudi Food and Drug Authority, "About SFDA," 2012. http://old.sfda.gov.sa/En/Home/Topics/about/ http://www.sfda.gov.sa/en/about/Pages/overview.aspx

[18] World Health Organization, "17th Model List of Essential Medicines," 2012. http://whqlibdoc.who.int/hq/2011/a95053_eng.pdf

[19] Saudi Ministry of Health, "Formulary: Drug List," 2012. http://www.moh.gov.sa/Portal/WhatsNew/Documents/M OHF_DRUG_LIST_CD.pdf

[20] K. K. Naidoo, P. Nompuku, S. N. Mkalali, K. Shabangu, L. Nkabinde and V. Singh, "Post-Marketing Stability Surveillance: Amoxicillin," South African Family Practice, Vol. 48, No. 6, 2006, pp. 14-14d. http://www.safpj.co.za/index.php/safpj/article/view/609/5 41

[21] R. B. Taylor, O. Shakoor, R. H. Behrens, M. Everard, A. S. Low, J. Wangboonskul, R. G. Reid and J. A. Kolawole, "Pharmacopeial Quality of Drugs Supplied by Nigerian Pharmacies," The Lancet, Vol. 357, No. 9272, 2011, pp. 1933-1936. http://dx.doi.org/10.1016/S0140-6736(00)05065-0

[22] U. Hadi, P. van den Broek, E. P. Kolopaking, N. Zairina, W. Gardjito and I. C. Gyssens, "Cross-Sectional Study of Availability and Pharmaceutical Quality of Antibiotics Requested with or without Prescription (over the Counter) in Surabaya, Indonesia," BMC Infectious Diseases, Vol. 10, No. 1, 2010, p. 203. http://dx.doi.org/10.1186/1471-2334-10-203

[23] T. A. O. Najjar, "A Survey on Community Pharmacies in Riyadh, Saudi Arabia," Saudi Pharmaceutical Journal, Vol. 9, No. 2, 2001, pp. 113-118.

[24] B. L. Hedt, C. Olives, M. Pagano and J. Valadez, "Large Country-Lot Quality Assurance Sampling: A New Method for Rapid Monitoring and Evaluation of Health, Nutrition and Population Programs at Sub-National Levels," The International Bank for Reconstruction and Development/The World Bank, Washington DC, 2008, pp. 31-32.

[25] S. Lemeshowand and S. Taber, "Lot Quality Assurance Sampling: Single- and Double-Sampling Plans," World Health Statistics Quarterly, Vol. 44, No. 3, 1991, pp. 115132.

[26] J. J. Valadez, R. Transgrud, M. Mbugua and T. Smith, "Assessing Family Planning Service-Delivery Skills in Kenya," Studies in Family Planning, Vol. 28, No. 2, 1997, pp. 143-150. http://dx.doi.org/10.2307/2138116

[27] Food and Nutrition Technical Assistance III Project, "LQAS Sample Size Calculator," 2012. http://www.fantaproject.org/calculators/samplesize_calcul ator.shtml

[28] P. T. Norris, "Purchasing Restricted Medicines in New Zealand Pharmacies: Results from a 'Mystery Shopper Study'," Pharmacy World and Science, Vol. 24, No. 4, 2002, pp. 149-153. http://dx.doi.org/10.1023/A:1019506120713

[29] J. M. Madden, J. D. Quick, D. Ross-Degnan and K. K. Kafle, "Undercover Careseekers: Simulated Clients in the Study of Health Provider Behavior in Developing Countries," Social Science \& Medicine, Vol. 45, No. 10, 1997, pp. 1465-1482. http://dx.doi.org/10.1016/S0277-9536(97)00076-2

[30] United States Pharmacopeial Convention, "United States Pharmacopeia and National Formulary (USP 34/NF 29)," United States Pharmacopeial Convention, Vol. 1, 2011, pp. 403-406.

[31] United States Pharmacopeial Convention, "United States Pharmacopeia and National Formulary (USP 34/NF 29)," United States Pharmacopeial Convention, Vol. 2, 2011, pp. 1882-1888.

[32] The Stationary Office, "British Pharmacopeia," The Stationary Office, Vol. 1, 2012, pp. 154-156.

[33] P. De Pourcq, J. Hoebus, E. Roets, J. Hoogmartens and H. Vanderhaeghe, "Quantitative Determination of Amoxicillin and Its Decomposition Products by High-Performance Liquid Chromatography," Journal of Chromatography, Vol. 321, No. 2, 1985, pp. 441-449. http://dx.doi.org/10.1016/S0021-9673(01)90462-5

[34] G. W. Fong, D. T. Martin, R. N. Johnson and B. T. Kho, "Determination of Degradation Products and Impurities of Amoxicillin Capsules Using Ternary Gradient Elution High-Performance Liquid Chromatography," Journal of Chromatography, Vol. 298, No. 3, 1984, pp. 459-472. http://dx.doi.org/10.1016/S0021-9673(01)92743-8 